\title{
Intra-articular lipoma of the knee joint located in the posterior compartment: A rare location
}

\author{
Mujdat Bankaoglu, ${ }^{1}$ Ozge Yapici Ugurlar, ${ }^{2}$ Meric Ugurlar, ${ }^{3}$ \\ Mesut Mehmet Sonmez, ${ }^{3}$ Osman Tugrul Eren ${ }^{3}$ \\ ${ }^{1}$ Department of Radiology, Sisli Hamidiye Etfal Training and Research Hospital, Istanbul, Turkey \\ 2Department of Radiology, Trakya University Faculty of Medicine, Edirne, Turkey \\ ${ }^{3}$ Department of Orthopedics and Traumatology, Sisli Hamidiye Etfal Training and Research Hospital, Istanbul, Turkey
}

\begin{abstract}
This report presents the case of a 51-year-old woman with intermittent left knee pain, especially during full flexion of the knee, which had been ongoing for 1 year. Magnetic resonance imaging (MRI) showed mild effusion and round mass at the posterior compartment without synovial changes. Computerized tomography (CT) indicated mass had homogeneous low attenuation and density measurement of $-99.4 \pm 62.3$ Hounsfield units (HU), correlated with a lipomatous lesion.
\end{abstract}

Keywords: Computerized tomography; CT; intra-articular lipoma; knee joint.

$\mathrm{L}$ ipomas are the most common soft-tissue tumors[1]. Intra-articular occurrence of true lipomas has been rarely reported in the literature, and they are mostly noted in the anterior aspect of the knee joint, especially on the Hoffa's fat pad and suprapatellar pouch [2-5]. The posterior compartment is an unusual location for solitary mass lesions of the knee joint [6]. According to our research of the literature, this article presents the first reported case of an intra-articular lipoma located in the posterior compartment, behind the posterior cruciate ligament.

\section{CASE REPORT}

A51-year-old woman presented with intermittent left knee pain, especially during flexion of the knee, which had been ongoing for 1 year. There was no history of trauma related to the knee joint, but there was a limitation of the knee during flexion. Physical examination revealed no swelling, palpable mass, erythema, or local heating. There was no instability of the joint. McMurray and Lachman tests, as well as anterior and posterior drawer test results were negative. Blood tests revealed a normal leukocyte count. Other laboratory tests were also unremarkable.

Radiography of the knee showed only mild osteodegenerative changes (Figure 1). Magnetic resonance imaging (MRI) showed medial meniscus degenerative changes, grade 2 chondral lesions

Received: December 07, 2015 Accepted: January 01, 2016 Online: May 02, 2016

Correspondence: Dr. Meric UGURLAR. Sisli Hamidiye Etfal Egitim ve Arastirma Hastanesi, Istanbul, Turkey. Tel: +90 212 - 3735000 e-mail: mugurlar@yahoo.com 
at the medial femoral and tibial condyles, mild effusion, and round mass at posterior compartment without synovial changes (Figures $2 \mathrm{~A}-\mathrm{C}$ ). A computerized tomography (CT) scan indicated the mass showed a well-defined, homogeneously low attenuated, hypodense nodular lesion at the posterior aspect of lateral femoral condyle. The density measurement of the mass on CT was $-99,4 \pm 62,3$ Hounsfield units (HU), correlated with a lipomatous lesion (Figure 3).

No biopsy was performed before the operation. Arthroscopic evaluation confirmed medial meniscus degeneration, and chondral lesions, as well as a yellowish synovial mass behind the posterior cruciate ligament. Mass was excised and referred for histopathological examination, which determined mass was adipose tissue and synovial tissue, confirming diagnosis of a synovial lipoma.

\section{DISCUSSION}

Though intra-articular lipomatous lesions are infrequent [3], there are two different benign types: the true lipoma and the more common lipoma arborescens [2]. Lipoma arborescens should be differentiated from true lipoma. Intra-articular true lipoma is defined as a solitary round or ovoid mass of fatty tissue contained in a thin, fibrous capsule and without synovial changes [7], while lipoma arborescens

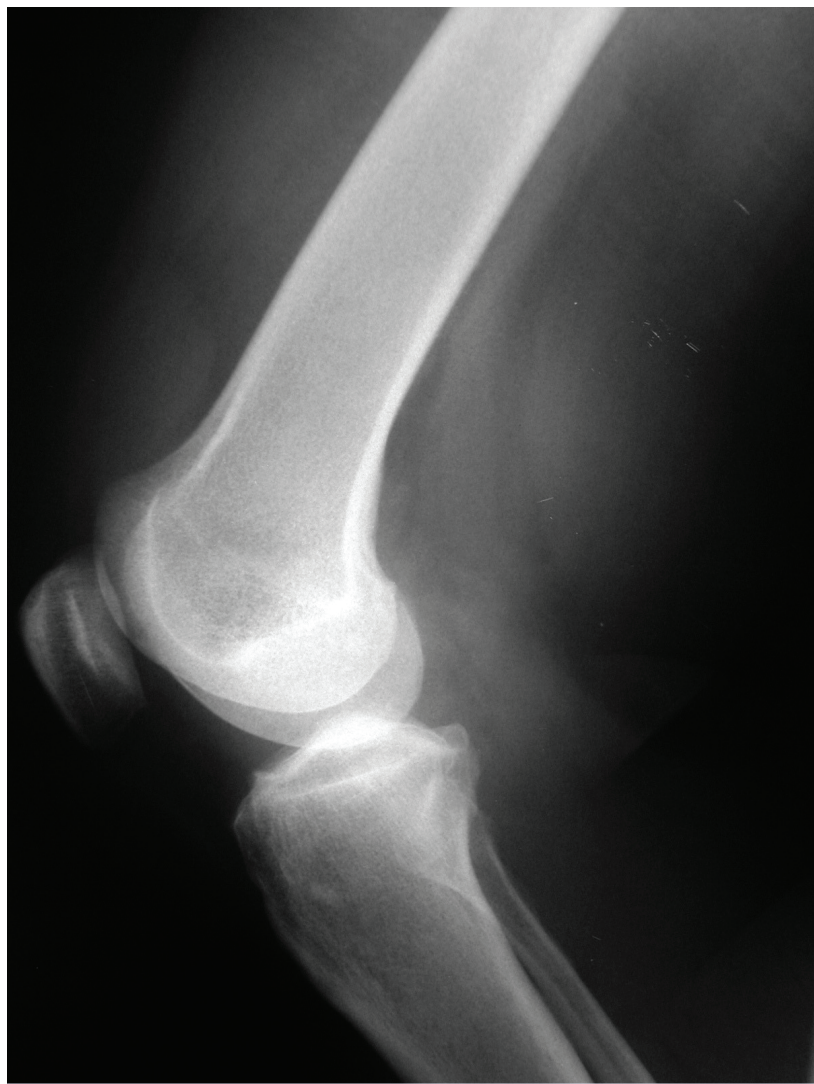

FIGURE 1. Lateral radiograph of the knee showed only mild osteodegenerative changes.

is characterized by a diffuse subsynovial deposit of fat and a villous appearance, associated with joint effusion and synovial cyst, and bone erosion [7].
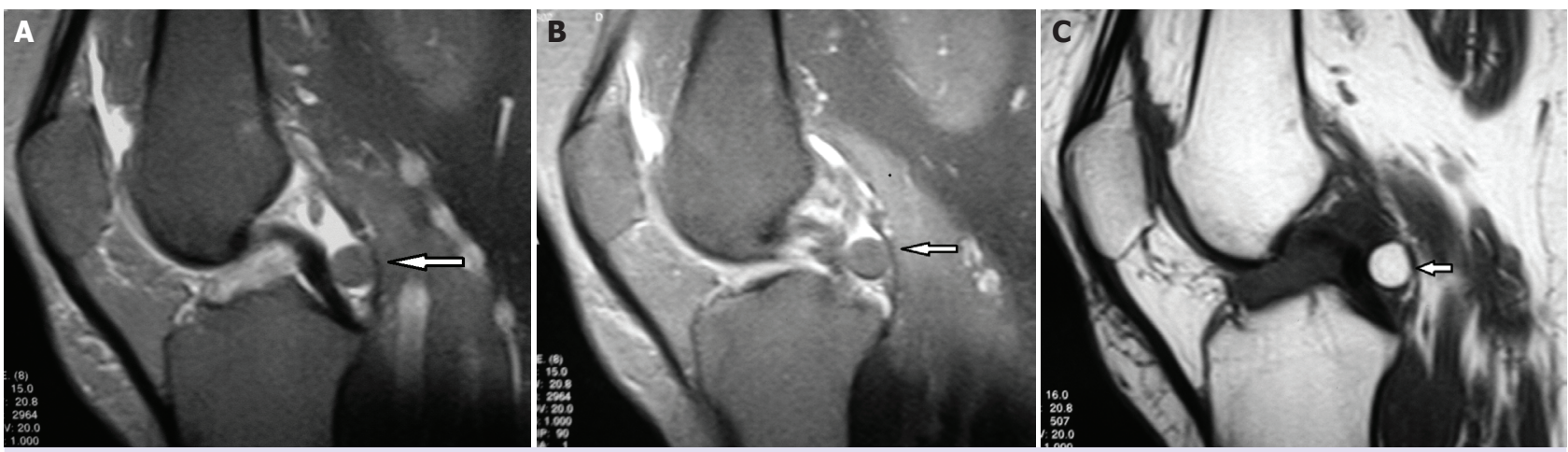

FIGURE 2. (A) In the sagittal fat-saturated T2-weighted MR image, there is round, nodular lesion behind the posterior cruciate ligament with distinct, regular margins isointense to the subcutaneous fatty tissue. (B) The sagittal fat-saturated T2-weighted MR image shows a thin, subtle, hypointense rim surrounding the lesion, consistent with a fibrous capsule. (C) In the sagittal T1-weighted MR image of the left knee, the lesion shows isointensity to subcutaneous fatty tissue. 


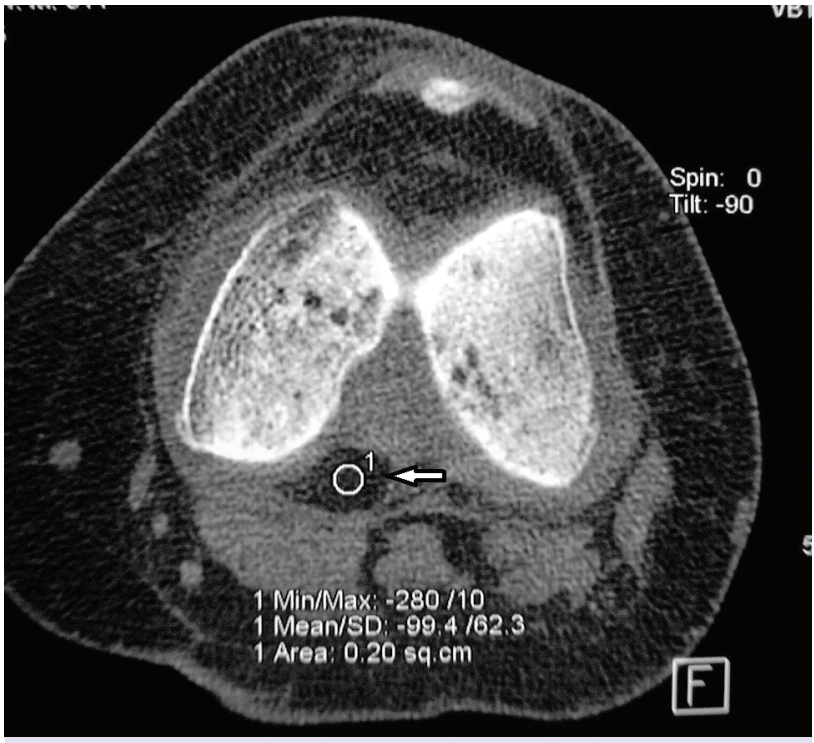

FIGURE 3. In the axial CT image of the left knee joint, at posterior aspect of lateral femoral condyle, there is round, homogenously hypodense nodular lesion with a density of $-99,4 \pm 62,3 \mathrm{HU}$, consistent with a lipoma.

Both intra-articular true lipoma and lipoma arborescens most commonly involve the knee joint [4], but lipoma arborescens is a synovial disorder that affects particularly the suprapatellar pouch [7]. True lipomas are mostly noted in anterior aspect of the knee joint, especially on the Hoffa's fat pad and suprapatellar pouch [2-5]. In the present case, the lesion did not arise within the synovium and did not fill the subsynovium as a lipoma arborescens does. Neither was there synovial overgrowth or villous, frond-like tissues, which are characteristics of lipoma arborescence.

Unlike other intra-articular lipoma cases, the lesion in this case was located at the posterior aspect of the knee joint, neighboring the posterior cruciate ligament (Figure 2A). The lesion had no obvious fibrous septa but it contained a fibrous capsule, which can be seen with a true lipoma (Figure $2 \mathrm{~B})$.

Ultrasonography (USG), CT and MRI are principal modalities used in radiological assessment of soft tissue tumors. The role of plain radiographs is limited in evaluation of lipomas but infrequently, the lesion may be identified as a low density, soft tissue mass. Lipomas close to the bone may cause osseous changes, such as hyperostosis, periostal reaction, remodeling or bony erosions and cartilaginous or osseous matrix within the masses [8]. In the present case, there were no osseous changes detected in plain radiographs (Figure 1). While USG can be used for diagnosis, the lipoma in this case was diagnosed solely with MRI. This is the major limitation of the report.

High resolution CT scan imaging is often diagnostic, even though MRI shows better soft tissue definition. On CT, lipomas generally appear as well-defined homogenous lesions. Benign lipomas have a homogeneous low attenuation on CT, with measurement of between -65 and $-120 \mathrm{HU}$ [9]. Although the HU value varies by specific body location, direct comparison with the attenuation of surrounding normal fat is often helpful [10]. In the present patient, measurement of the mass was in fat density (-99.4 HU), correlated with the lipomatous lesion.

Posterior compartment is an unusual location for solitary mass lesions of the knee joint [6]. According to our research of the literature, there are two reported cases of solitary, intra-articular lipoma occurring in the femoral intercondylar notch $[4,5]$. Thus, according to the radiological work- up, we diagnosed this lesion as lipoma.

\section{Learning points}

1. Intra-articular occurrence of lipomas is rare.

2. They are usually reported in the anterior aspect of the knee joint.

3. It should be kept in mind by radiologists and orthopedic surgeons that they can be found in the posterior aspect.

4. True lipoma and lipoma arborescens are benign lipomatous lesions of the knee joint.

5. Lipoma arborescens should be differentiated from true lipoma.

6. High resolution CT scan imaging is often diagnostic.

7. MRI shows better soft tissue definition. 
Conflict of Interest: None declared.

Financial Disclosure: The authors declared that this study has received no financial support.

Authorship contributions: Concept, M.U.; Design, M.U.; Supervision, M.M.S.; Materials, M.B.; Data collection and/ or processing, M.B., Ö.Y.U.; Analysis and/or interpretation, Ö.Y.U.; Literature search, M.M.S.; Writing, M.U.; Critical review, O.T.E.

\section{REFERENCES}

1. Rydholm A, Berg NO. Size, site and clinical incidence of lipoma. Factors in the differential diagnosis of lipoma and sarcoma. Acta Orthop Scand 1983;54:929-34.

2. Lee F, Keel SB, Gebhardt MC, Rosenthal DI. Intra-articular lipoma with osteochondroid metaplasia in the knee joint. Skeletal Radiol 2001;30:230-3.

3. Matsumoto K, Okabe H, Ishizawa M, Hiraoka S. Intra-articular lipoma of the knee joint. A case report. J Bone Joint Surg Am 2001;83-A:101-5.

4. Yamaguchi S, Yamamoto T, Matsushima S, Yoshiya S, Matsub- ara N, Matsumoto T. Solitary intraarticular lipoma causing sudden locking of the knee: a case report and review of the literature. Am J Sports Med 2003;31:297-9.

5. Motsis E, Vasiliadis HS, Xenakis TA. Intraarticular synovial lipoma of the knee located in the intercondylar notch, between ACL and PCL: a case report and review of the literature. Knee Surg Sports Traumatol Arthrosc 2005;13:683-8.

6. Ozalay M, Tandoğan RN, Akpinar S, Cesur N, Hersekli MA, Ozkoç G, et al. Arthroscopic treatment of solitary benign intraarticular lesions of the knee that cause mechanical symptoms. Arthroscopy 2005;21:12-8.

7. Ryu KN, Jaovisidha S, Schweitzer M, Motta AO, Resnick D, MR imaging of lipoma arborescens of the knee joint. AJR Am J Roentgenol 1996;167:1229-32.

8. Knapp EL, Kransdorf MJ, Letson GD. Diagnostic imaging update: soft tissue sarcomas. Cancer Control 2005;12:22-6.

9. Munk PL, Lee MJ, Janzen DL, Connell DG, Logan PM, Poon PY, et al. Lipoma and liposarcoma: evaluation using CT and MR imaging. AJR Am J Roentgenol 1997;169:589-94.

10. Murphey MD, Carroll JF, Flemming DJ, Pope TL, Gannon FH, Kransdorf MJ. From the archives of the AFIP: benign musculoskeletal lipomatous lesions. Radiographics 2004;24:1433-66. 